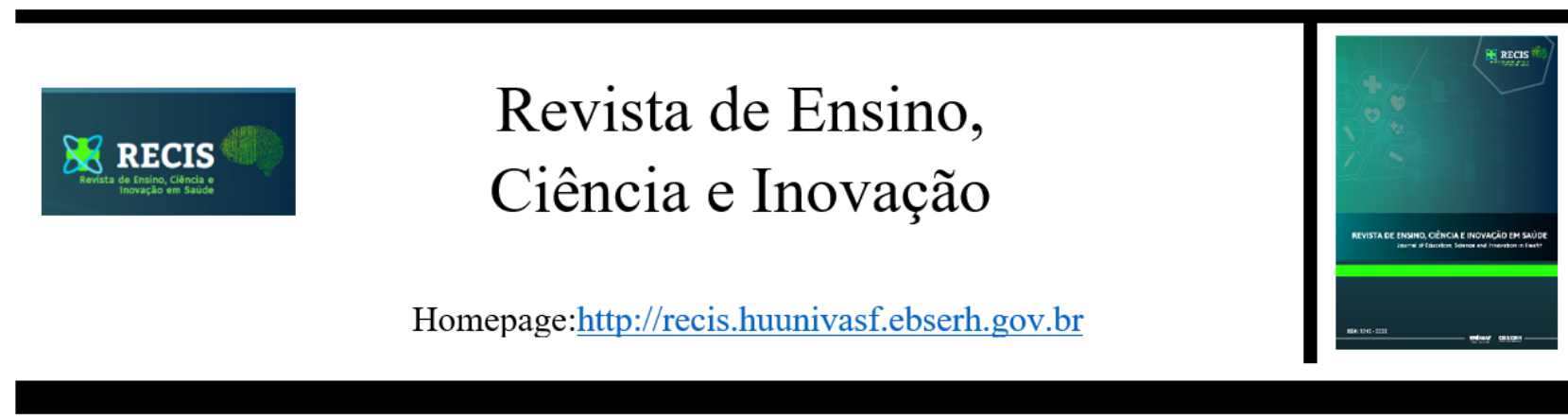

\title{
Perfil bacteriano de amostras biológicas da clínica médica de um Hospital Universitário do Sertão de Pernambuco
}

\section{Bacterial profile of biological samples from the medical clinic of a University Hospital in Sertão de Pernambuco}

\section{Ive Dias Mangueira Bastos' ${ }^{1}$ Bruna Dias Mangueira Bastos², Kátia Suely Batista Silva1, Carine Freitas Silva ${ }^{3}$, Carine Rosa Naue ${ }^{1}$}

\begin{abstract}
${ }^{1}$ Hospital Universitário da Universidade Federal do Vale do São Francisco, ${ }^{2}$ Universidade Federal do Vale do São Francisco, ${ }^{3}$ Faculdade São Francisco de Juazeiro
\end{abstract}

Autor correspondente: ivedmb@gmail.com

Artigo recebido em 05/10/2020 e aceito em 22/11/2020

\begin{abstract}
RESUMO
As infecções relacionadas a assistência à saúde (IRAS) são um desafio de saúde pública por causarem aumento da morbidade e mortalidade, do tempo de internação para o indivíduo e dos custos hospitalares. O objetivo deste trabalho foi verificar o perfil bacteriano de hemoculturas, secreções traqueais e uroculturas de pacientes internados na Clínica Médica de um Hospital Universitário. O estudo foi realizado através da análise retrospectiva destes exames em pacientes internados no período de junho de 2018 a julho de 2019. Os dados foram coletados por meio de impressos laboratoriais do próprio serviço e tabulados na planilha do Excel®, sendo divididos em amostras positivas e negativas e realizada análise descritiva com valores absolutos e percentuais. As principais espécies bacterianas isoladas nas secreções traqueais, hemoculturas e uroculturas foram Pseudomonas aeruginosa (30\%), Staphylococcus coagulase negativa (20\%) e Klebsiella pneumoniae (30\%), respectivamente. Para a maioria das bactérias analisadas, independente das amostras, foi verificada uma alta resistência bacteriana. O conhecimento das espécies mais ocorrentes, assim como da elevada resistência observada, permite que os profissionais de saúde estabeleçam protocolos preventivos e realizem tratamentos mais efetivos.
\end{abstract}

Palavras-chave: Ocorrência; Bactérias; Amostras biológicas; Clínica médica.

\footnotetext{
ABSTRACT

As health care-related infections (HAIs) are a public health challenge because they increase morbidity and mortality, length of hospital stay for individuals and hospital costs. The objective of this work was to verify the bacterial profile of blood cultures, tracheal secretions and urine cultures of patients admitted to the Medical Clinic of an University Hospital. The study was carried out through the retrospective analysis of these exams in patients hospitalized from June 2018 to July 2019. Data were collected through impressions from individual laboratory laboratories and planned in an Excel® spreadsheet, being divided into specific items and negative and descriptive analyzes were performed with absolute and percentage values. The main bacterial species isolated in the tracheal sections, blood cultures and urine cultures were Pseudomonas aeruginosa (30\%), Staphylococcus coagulase negative (20\%) and Klebsiella pneumoniae (30\%), respectively. For most of the bacteria analyzed, regardless of the samples, a high bacterial resistance was verified. Knowledge of the most recent species, such as the high resistance observed, allows health professionals to establish preventive and achievable, more effective protocols.

Keywords: Occurrence; Bacteria; Biological samples; Medical clinic.
} 


\section{INTRODUÇÃO}

As Infecções Relacionadas à Assistência em Saúde (IRAS) são infecções adquiridas e relacionadas à assistência durante a internação em estabelecimentos de saúde ou no atendimento domiciliar. ${ }^{1}$ Essas infecções representam um dos principais motivos para elevação dos índices de morbimortalidade. Milhões de pacientes são acometidos por IRAS em todo o mundo a cada ano, levando a uma mortalidade expressiva e prejuízos financeiros para os sistemas de saúde. ${ }^{2}$

Segundo dados da Organização Mundial de Saúde (OMS) coletados entre 1996 a 2008, pesquisas realizadas em países em desenvolvimento sinalizam valores percentuais de IRAS maiores do que os advindos de países desenvolvidos (3,5 a 12\%). As taxas de prevalência nestas instituições variaram de 5\% a 19\%, sendo a maior parte com dados superiores a $10 \%$. No Brasil, a prevalência alcança $14 \% .^{3}$ Vale ressaltar que o índice de IRAS varia expressivamente, pois está diretamente associado com o nível de atendimento e complexidade de cada unidade hospitalar, relacionando-se assim, com a triagem de pacientes na admissão no hospital ${ }^{4}$. Embora as causas de IRAS estejam intimamente relacionadas com a suscetibilidade do paciente frente à atmosfera hospitalar, bem como os métodos diagnósticos e terapêuticos utilizados, a principal causa ainda corresponde as condições de controle microbiano, higiene do ambiente hospitalar e a qualidade de colonização dos indivíduos hospitalizados. $^{4}$

Desde 2008, a Agência Nacional de Vigilância Sanitária (ANVISA) desenvolve estudos contendo critérios diagnósticos das infecções mais freqüentes relacionadas aos serviços de saúde. Desde então, percebeu-se que alguns tipos de infecção assumem maior importância, entre as principais IRAS, encontra-se as pneumonias, normalmente relacionadas à ventilação mecânica; as infecções primárias de corrente sanguínea (IPCS); as infecções do trato urinário (ITU), que estão comumente relacionadas aos dispositivos invasivos utilizados na assistência ao paciente e as infecções de sítio cirúrgico (ISC) que ocorrem por ocasião do próprio serviço hospitalar. $^{5}$

Entre os micro-organismos que causam IRAS, as bactérias ganham destaque por constituírem a microbiota do ser humano e colonizarem diversos sítios anatômicos, podendo oportunamente, causar infecção em indivíduos com estado clínico imuno comprometido. ${ }^{6}$
Para o manejo destas infecções bacterianas nosocomiais, o consumo de antimicrobianos tem aumentado consideravelmente e merece atenção especial nos últimos anos, em decorrência às crescentes preocupações com a emergência de cepas de micro-organismos multirresistentes. A resistência aos antimicrobianos é uma estratégia de sobrevivência dos agentes microbianos, sendo uma consequência inevitável da utilização e agravada com o uso incorreto ou indiscriminado dos mesmos. ${ }^{7}$

O conhecimento desses agentes e seu grau de resistência em determinada unidade de saúde, pode ser utilizado como referência para tratamentos mais eficientes, permitindo a redução da resistência bacteriana.

Diante do exposto, o objetivo deste trabalho foi verificar a ocorrência e o perfil bacteriano em hemoculturas, secreções traqueais e uroculturas de pacientes internados na Clínica Médica de um Hospital Universitário.

\section{MATERIAL E MÉTODOS}

O trabalho foi realizado utilizando dados de um Hospital Universitário do Sertão do Vale do São Francisco, que conta com o perfil assistencial de hospital geral de média e alta complexidade à comunidade adulta, com dimensionamento dos serviços assistenciais e de ensino e pesquisa.

A pesquisa trata-se de um estudo observacional, retrospectivo e descritivo com abordagem quantitativa, cujos dados foram coletados por meio de impressos laboratoriais do próprio serviço. Foram analisados exames de secreções traqueais, hemoculturas e uroculturas de pacientes internados na Clínica Médica, no período de junho de 2018 a julho de 2019.

Os dados dos exames foram tabulados na planilha do Excel®, onde foram divididos em amostras positivas e negativas e realizada análise descritiva com valores absolutos e em percentuais. Foram consideradas amostras positivas para urocultura quando a contagem de colônias foi maior ou igual a $100.000 \mathrm{UFC} / \mathrm{ml}$, para hemocultura quando houve qualquer crescimento bacteriano e para cultura de secreção traqueal quando a contagem de colônias foi maior ou igual a $10^{6} \mathrm{UFC} / \mathrm{ml}$. Nas amostras positivas foi avaliada a resistência aos antibióticos testados. Os dados foram organizados e apresentados por meio de gráficos e tabelas.

As identificações das bactérias e os antibiogramas foram executados através do sistema automatizado PHOENIX, da BD, utilizando-se os 
painéis adequados. De acordo com a metodologia do Clinical and Laboratory Standards Institute (2018 e 2019), os resultados foram classificados em sensível (S) e resistente (R).

O trabalho foi submetido ao Comitê de Ética da Universidade Federal do Vale do São Francisco (UNIVASF), sendo aprovado através do CAAE: 66493917.0.0000.5196.

\section{RESULTADOS}

Em relação aos aspirados traqueais no período do estudo, em um total de 49 amostras colhidas, o número de casos positivos para crescimento bacteriano foi de 44 amostras $(89,7 \%)$. As principais espécies bacterianas identificadas, como se observa na Figura 1, foram Pseudomonas aeruginosa (30\%), Klebsiella pneumoniae (20\%), Acinetobacter baumanni (14\%) e o Staphylococcus aureus (14\%). Houve, ainda, outras bactérias com menor incidência identificadas, porém quando somadas resultavam em $23 \%$.

Pode-se observar, na Tabela 1, o perfil de resistência das bactérias mais ocorrentes, isoladas em aspirados traqueais de pacientes internados na Clínica Médica do Hospital Universitário.

Os isolados de K.pneumoniae apresentaram os percentuais de resistência de $100 \%$ para ampicilina e cefuroxima; $67 \%$ para cefepime e ceftriaxona; $63 \%$ para cefazolina; $57 \%$ para ampicilina sulbactam; $56 \%$ para ciprofloxacino, levofloxacino e sulfametoxazol + trimetoprima; $50 \%$ para amoxicilina + clavulanato; $44 \%$ para gentamicina e piperacilina + tazobactam; $33 \%$ para cefoxitina, ertapenem e meropenem e $11 \%$ para imipenem. Todos os isolados de $K$. pneumoniae foram $100 \%$ sensível a amicacina, colistina e tigeciclina (Tabela 1).

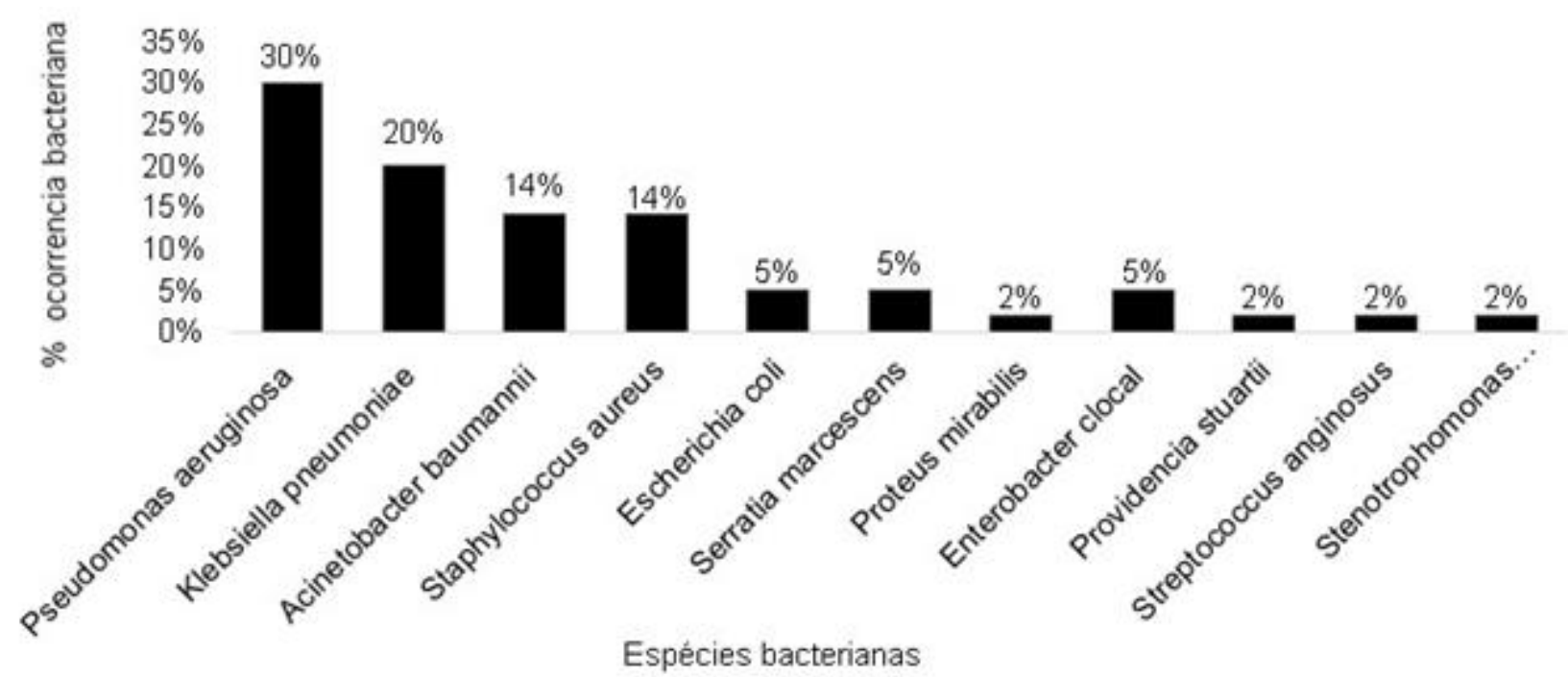

Figura 1. Ocorrência de bactérias isoladas em aspirados traqueais coletadas em pacientes internados na Clínica Médica do Hospital Universitário, no período de junho de 2018 a julho de 2019

Em relação aos isolados de $P$. aeruginosa foram observados os percentuais de resistência de 50\% para imipenem; $38 \%$ para meropenem; $31 \%$ para cefepime e ceftriaxona; $23 \%$ para ceftazidina, gentamicina e levofloxacino; $15 \%$ para ampicilina; $8 \%$ para clorafenicol. Todos os isolados foram $100 \%$ sensíveis a piperacilina + tazobactam e a minociclina (Tabela 1).

Para A. baumannii foram observados os percentuais de resistência de $100 \%$ para meropenem, piperacilina + tazobactam e imipenem; $83 \%$ para ampicilina, cefepime, ceftazidina, ciprofloxacino, gentamicina, levofloxacino e sulfametoxazol + trimetoprima e $67 \%$ para ampicilina +sulbactam. Todos os isolados foram $100 \%$ sensíveis a colistina (Tabela $1)$.

Os isolados de S. aureus apresentaram os percentuais de resistência de $100 \%$ para azitromicina e penicilina; $67 \%$ para ampicilina, clindamicina e eritromicina; $40 \%$ para oxacilina; $25 \%$ para ceftarolina; $17 \%$ para sulfametoxazol + trimetoprima. Todos isolados foram $100 \%$ sensíveis a ciprofloxacino, doxiciclina, gentamicina, linezolide, minociclina, rifampicina, tigeciclina, vancomicina e tetraciclina (Tabela 1). 
Revista de Ensino, Ciência e Inovação em Saúde v.1, n. 1 (2020) 4-15

Tabela 1: Perfil de resistência das bactérias mais ocorrentes isoladas de aspirados traqueais coletados em pacientes internados na Clínica Médica de do Hospital Universitário, no período de junho de 2018 a julho de 2019

Antimicrobianos Espécies bacterianas
K. pneumoniae
P. aeruginosa
A. baumannii
S. aureus

\begin{tabular}{|c|c|c|c|c|c|c|c|c|}
\hline & $\mathbf{n}$ & $\%$ & $\mathbf{n}$ & $\%$ & $\mathbf{n}$ & $\%$ & $\mathbf{n}$ & $\%$ \\
\hline Ampicilina & 9 & 100 & 2 & 15 & 5 & 83 & 2 & 67 \\
\hline Amicacina & 9 & 0 & NT & NT & NT & NT & NT & NT \\
\hline Azitromicina & NT & NT & NT & NT & NT & NT & 1 & 100 \\
\hline Amp+sub & 4 & 57 & NT & NT & 4 & 67 & NT & NT \\
\hline Amox +clav & 1 & 50 & NT & NT & NT & NT & NT & NT \\
\hline Cefepime & 6 & 67 & 4 & 31 & 5 & 83 & NT & NT \\
\hline Ceftazidina & NT & NT & 3 & 23 & 5 & 83 & NT & NT \\
\hline Cefazolina & 5 & 63 & NT & NT & NT & NT & NT & NT \\
\hline Cefoxitina & 3 & 33 & NT & NT & NT & NT & NT & NT \\
\hline Cefuroxima & 2 & 100 & NT & NT & NT & NT & NT & NT \\
\hline Ceftarolina & NT & NT & NT & NT & NT & NT & 1 & 25 \\
\hline Ceftriaxona & 6 & 67 & 4 & 31 & NT & NT & NT & NT \\
\hline Ciprofloxacino & 5 & 56 & NT & NT & 5 & 83 & 1 & 0 \\
\hline Cloranfenicol & NT & NT & 1 & 8 & NT & NT & NT & NT \\
\hline Colistina & 6 & 0 & NT & NT & 6 & 0 & NT & NT \\
\hline Clindamicina & NT & NT & NT & NT & NT & NT & 4 & 67 \\
\hline Doxiciclina & NT & NT & NT & NT & NT & NT & 1 & 0 \\
\hline Eritromicina & NT & NT & NT & NT & NT & NT & 4 & 67 \\
\hline Ertapnem & 3 & 33 & NT & NT & NT & NT & NT & NT \\
\hline Gentamicina & 4 & 44 & 3 & 23 & 5 & 83 & 1 & 0 \\
\hline Imipenem & 1 & 11 & 6 & 50 & 6 & 100 & NT & NT \\
\hline Linezolide & NT & NT & NT & NT & NT & NT & 6 & 0 \\
\hline Levofloxacino & 5 & 56 & 3 & 23 & 5 & 83 & NT & NT \\
\hline Oxacilina & NT & NT & NT & NT & NT & NT & 2 & 40 \\
\hline Minociclina & NT & NT & NT & 0 & NT & NT & 5 & 0 \\
\hline Meropenem & 3 & 33 & 5 & 38 & 6 & 100 & NT & NT \\
\hline Penicilina & NT & NT & NT & NT & NT & NT & 5 & 100 \\
\hline Pipe+taz & 4 & 44 & 13 & 0 & 6 & 100 & NT & NT \\
\hline Rifampicina & NT & NT & NT & NT & NT & NT & 6 & 0 \\
\hline Smt+tmp & 5 & 56 & NT & NT & 5 & 83 & 1 & 17 \\
\hline Tigeciclina & 7 & 0 & NT & NT & NT & NT & 5 & 0 \\
\hline Tetraciclina & NT & NT & NT & NT & NT & NT & 0 & 0 \\
\hline Vancomicina & NT & NT & NT & NT & NT & NT & 1 & 0 \\
\hline
\end{tabular}

NT: não testado; n: número de isolados bacterianos; \%: percentual de resistência; pipe+tazo: piperacilina + tazobactam; smt+tmp:sulfametoxazol + trimetoprima; amp+sub: ampicilina + sulbactam; amox+clav: amoxicilina + clavulanato.

Para hemoculturas (Figura 2) no período de junho de 2018 a julho de 2019, em um total de 336 amostras colhidas, o número de casos positivos foi de 52 amostras $(15,4 \%)$. As espécies mais frequentes foram $S$. coagulase negativa( $31 \%), S$. aureus (17\%), K. pneumoniae (10\%), Enterococcus faecalis (8\%) e Escherichia coli $(8 \%)$. Houve ainda, outras bactérias com menor ocorrência, porém quando somadas resultavam em $28 \%$. 


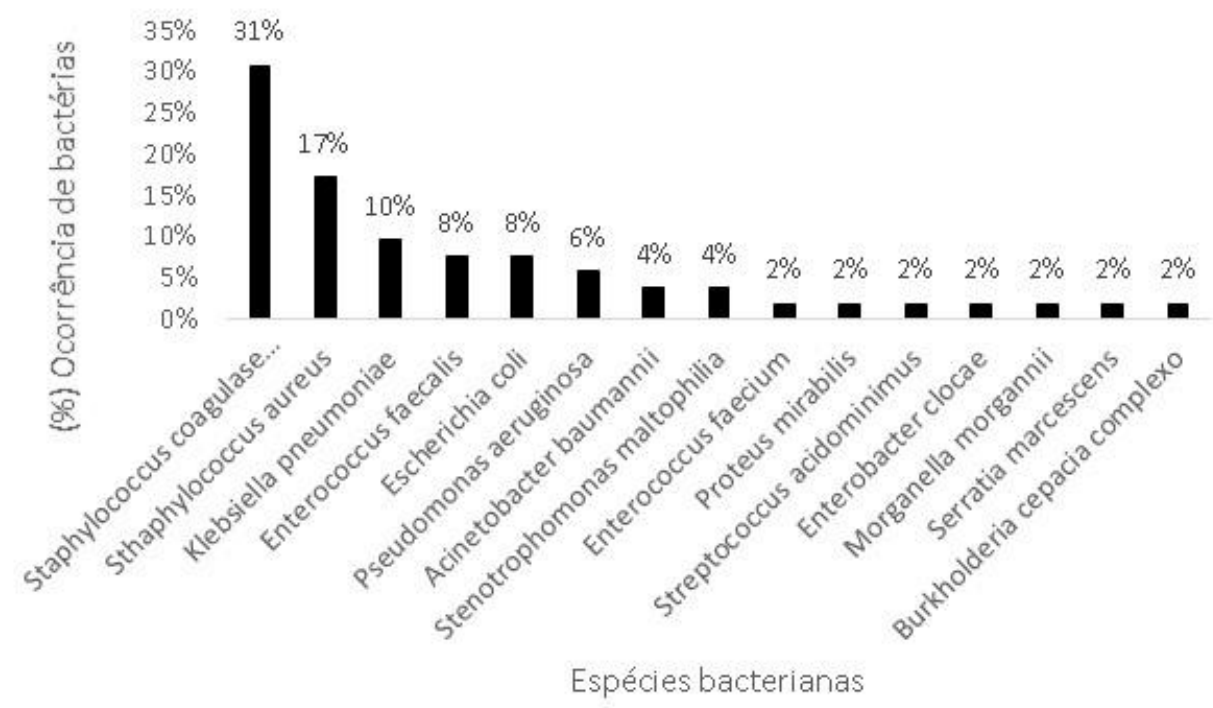

Figura 2. Ocorrência de bactérias isoladas em hemoculturas coletadas em pacientes internados na Clínica Médica do Hospital Universitário, no período de junho de 2018 a julho de 2019

$\mathrm{Na}$ Tabela 2 observa-se o perfil de resistência das bactérias mais ocorrentes isoladas em hemoculturas de pacientes internados na Clínica Médica do Hospital Universitário.

Os isolados de $S$. coagulase negativa (SCN) apresentaram os percentuais de resistência de $100 \%$ para ampicilina, eritromicina, levofloxacino, penicilina e piperacilina + tazobactam; $88 \%$ para oxacilina e clindamicina; $57 \%$ para sulfametoxazol + trimetoprima e $31 \%$ para rifampicina. Todos os isolados de $\mathrm{SCN}$ foram $100 \%$ sensível à vancomicina,linezolide, daptomicina e minociclina (Tabela 2).

Os isolados de $S$. aureus apresentaram os percentuais de resistência de $100 \%$ para ampicilina, penicilina e piperacilina + tazobactam; $56 \%$ para clindamicina e eritromicina; $33 \%$ para oxacilina e $100 \%$ de sensibilidade para ceftarolina, daptomicina, linezolide, minociclina, rifampicina, sulfametoxazol + trimetoprima, tigeciclina $\mathrm{e}$ vancomicina (Tabela 2)

Para os isolados de K. pneumoniae foram observados os percentuais de resistência de $100 \%$ para ampicilina, ceftarolina e ciprofloxacino; $60 \%$ para ampicilina + sulbactam, cefepime, ceftriaxona e sulfametoxazol + trimetoprima; $50 \%$ para cefazolina; $20 \%$ para levofloxacino e piperacilina + tazobactam. Todos os isolados foram $100 \%$ sensíveis a amicacina, cefoxitina, daptomicina, ertapenem, gentamicina, colistina, imipenem, meropenem e tigeciclina (Tabela 2).

Os isolados de E. faecalis apresentaram os percentuais de resistência de $100 \%$ paraceftarolina e $100 \%$ de sensibilidade para sensível ampicilina, daptomicina, linezolide, penicilina, tigeciclina e vancomicina (Tabela 2).
Em relação aos isolados de E. Coli pode-se observar $75 \%$ de resistência para ampicilina; $50 \%$ para ampicilina + sulbactam, cefepime e ceftriaxona; $33 \%$ para ceftazidina; $25 \%$ para ciprofloxacino, gentamicina elevofloxacino. Todos os isolados foram $100 \%$ sensíveis amicacina, cefoxitina, colistina, ertapenem, imipenem, piperacilina + tazobactam e tigeciclina(Tabela 2).

Para uroculturas (Figura 3) em um total de 291 amostras colhidas, o número de casos positivos foi de 47 amostras $(16,1 \%)$. As espécies mais frequentes foram $K$. pneumoniae $(30 \%), E$. coli(26\%), Proteus mirabilis (11\%), E. faecalis (9\%) e A. baumannii (9\%). Houve, ainda, outras bactérias com menor incidência identificadas, porém quando somadas resultaram em $20 \%$.

Pode-se observar, na Tabela 3, o perfil de resistência das bactérias mais ocorrentes isoladas em urocultura de pacientes internados na Clínica Médica do Hospital Universitário.

Os isolados de $K$. pneumoniae apresentaram os percentuais de resistência de $100 \%$ para ampicilina, ceftazidina e cefazolina; $80 \%$ para ampicilina + sulbactam; $79 \%$ para cefepime, ceftriaxona e sulfametoxazol + trimetoprima; $75 \%$ para amoxilina + clavulanato e cefuroxima; $64 \%$ para ciprofloxacino, levofloxacino e gentamicina; 50\% para nitrofurantoina; $57 \%$ para piperacilina + tazobactam; $43 \%$ para ertapenem e cefoxitina; $39 \%$ para meropenem; $24 \%$ para imipenem e $13 \%$ para colistina (Tabela 3 ). Todos os isolados foram $100 \%$ sensíveis a amicacina e tigeciclina. 
Tabela 2: Perfil de resistência das bactérias mais ocorrentes isoladas de hemoculturas coletadas em pacientes internados na Clínica Médica do Hospital Universitário, no período de junho de 2018 a julho de 2019

\begin{tabular}{|c|c|c|c|c|c|c|c|c|c|c|}
\hline \multirow[t]{3}{*}{ Antimicrobianos } & \multicolumn{10}{|c|}{ Espécies bacterianas } \\
\hline & \multicolumn{2}{|c|}{$\begin{array}{c}S . \text { coagulase } \\
\text { negativa }\end{array}$} & \multicolumn{2}{|c|}{$\begin{array}{c}S . \\
\text { aureus }\end{array}$} & \multicolumn{2}{|c|}{$\begin{array}{c}\text { K. } \\
\text { pneumoniae }\end{array}$} & \multicolumn{2}{|c|}{$\begin{array}{c}E . \\
\text { faecalis }\end{array}$} & \multicolumn{2}{|c|}{$\begin{array}{c}E . \\
\text { Coli }\end{array}$} \\
\hline & $\mathrm{N}$ & $\%$ & $\mathrm{~N}$ & $\%$ & $\mathrm{~N}$ & $\%$ & $\mathrm{~N}$ & $\%$ & $\mathrm{~N}$ & $\%$ \\
\hline Ampicilina & 6 & 100 & 2 & 100 & 4 & 100 & 4 & 0 & 3 & 75 \\
\hline Amicacina & NT & NT & NT & NT & 5 & 0 & NT & NT & 4 & 0 \\
\hline Amp+sub & NT & NT & NT & NT & 3 & 60 & NT & NT & 2 & 50 \\
\hline Cefepime & NT & NT & NT & NT & 3 & 60 & NT & NT & 2 & 50 \\
\hline Ceftazidina & NT & NT & NT & NT & NT & NT & NT & NT & 1 & 33 \\
\hline Cefazolina & NT & NT & NT & NT & 2 & 50 & NT & NT & NT & NT \\
\hline Cefoxitina & NT & NT & NT & NT & 5 & 0 & NT & NT & 4 & 0 \\
\hline Cefuroxima & NT & NT & NT & NT & NT & NT & NT & NT & NT & NT \\
\hline Ceftarolina & NT & NT & 6 & 0 & 4 & 100 & 4 & 100 & NT & NT \\
\hline Ceftriaxona & NT & NT & NT & NT & 3 & 60 & NT & NT & 2 & 50 \\
\hline Ciprofloxacino & NT & NT & NT & NT & 1 & 100 & NT & NT & 1 & 25 \\
\hline Clorafenicol & NT & NT & NT & NT & NT & NT & NT & NT & NT & NT \\
\hline Colistina & NT & NT & NT & NT & 4 & 0 & NT & NT & 4 & 0 \\
\hline Clindamicina & 14 & 88 & 5 & 56 & NT & NT & NT & NT & NT & NT \\
\hline Daptomicina & 15 & 0 & 9 & 0 & 4 & 0 & 4 & 0 & NT & NT \\
\hline Eritromicina & 16 & 100 & 5 & 56 & NT & NT & NT & NT & NT & NT \\
\hline Ertapenem & NT & NT & NT & NT & 5 & 0 & NT & NT & 4 & 0 \\
\hline Getamicina & NT & NT & NT & NT & 5 & 0 & NT & NT & 1 & 25 \\
\hline Imipenem & NT & NT & NT & NT & 5 & 0 & NT & NT & 4 & 0 \\
\hline Linezolide & 15 & 0 & 9 & 0 & NT & NT & 4 & 0 & NT & NT \\
\hline Levofloxacino & 1 & 100 & NT & NT & 1 & 20 & NT & NT & 1 & 25 \\
\hline Meropenem & NT & NT & NT & NT & 5 & 0 & NT & NT & NT & NT \\
\hline Oxacilina & 14 & 88 & 3 & 33 & NT & NT & NT & NT & NT & NT \\
\hline Minociclina & 15 & 0 & 9 & 0 & NT & NT & NT & NT & NT & NT \\
\hline Penicilina & 4 & 100 & 3 & 100 & NT & NT & 4 & 0 & NT & NT \\
\hline Pipe+tazo & 6 & 100 & 4 & 100 & 1 & 20 & NT & NT & 4 & 0 \\
\hline Rifampicina & 5 & 31 & 9 & 0 & NT & NT & NT & NT & NT & NT \\
\hline Smt+tmp & 8 & 57 & 9 & 0 & 3 & 60 & NT & NT & NT & NT \\
\hline Tigeciclina & NT & NT & 6 & 0 & 5 & 0 & 4 & 0 & 4 & 0 \\
\hline Vancomicina & 2 & 0 & 9 & 0 & NT & NT & 4 & 0 & NT & NT \\
\hline
\end{tabular}

NT: não testado; n: número de isolados bacterianos; \%: percentual de resistência; pipe+tazo: piperacilina + tazobactam; smt+tmp:sulfametoxazol + trimetoprima; amp+sub: ampicilina + sulbactam; amox+clav: amoxicilina + clavulanato.

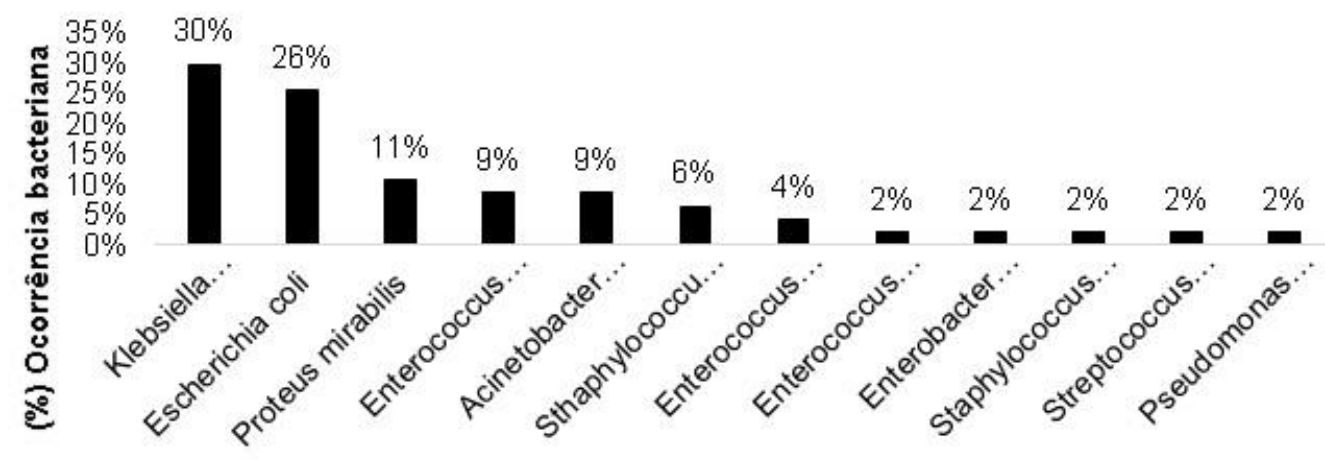

Espécies bacterianas

Figura 3. Ocorrência de bactérias isoladas em uroculturas coletadas em pacientes internados na Clínica Médica do Hospital Universitário, no período de junho de 2018 a julho de 2019 
Tabela 3. Perfil de resistência das bactérias mais ocorrentes isoladas de uroculturas coletadas em pacientes internados na Clínica Médica do Hospital Universitário, no período de junho de 2018 a julho de 2019

Antimicrobianos Espécies bacterianas
K. pneumoniae
E. coli
E.faecalis
P. mirabilis
A. baumannii

\begin{tabular}{|c|c|c|c|c|c|c|c|c|c|c|}
\hline & $\mathrm{N}$ & $\%$ & $\mathrm{~N}$ & $\%$ & $\mathrm{~N}$ & $\%$ & $\mathrm{~N}$ & $\%$ & $\mathrm{~N}$ & $\%$ \\
\hline Ampicilina & 14 & 100 & 6 & 86 & 4 & 0 & 1 & 20 & NT & NT \\
\hline Amicacina & 14 & 0 & 12 & 0 & NT & NT & 1 & 20 & 4 & 100 \\
\hline Aztreonam & NT & NT & 1 & 0 & NT & NT & NT & NT & NT & NT \\
\hline Amp+sub & 8 & 80 & 5 & 71 & NT & NT & 4 & 0 & 1 & 50 \\
\hline Amox + clav & 3 & 75 & 3 & 60 & NT & NT & 1 & 0 & NT & NT \\
\hline Cefepime & 11 & 79 & 6 & 50 & NT & NT & 4 & 0 & 4 & 100 \\
\hline Ceftazidina & 8 & 100 & NT & NT & NT & NT & NT & NT & 4 & 100 \\
\hline Cefazolina & 8 & 100 & 5 & 100 & NT & NT & NT & NT & NT & NT \\
\hline Cefoxitina & 6 & 43 & 11 & 0 & NT & NT & 5 & 0 & NT & NT \\
\hline Cefuroxima & 3 & 75 & 4 & 80 & NT & NT & 2 & 0 & NT & NT \\
\hline Ceftarolina & NT & NT & NT & NT & 4 & 100 & NT & NT & NT & NT \\
\hline Ceftriaxona & 11 & 79 & 7 & 64 & NT & NT & 4 & 0 & NT & NT \\
\hline Cefotaxima & NT & NT & NT & NT & NT & NT & 1 & 0 & NT & NT \\
\hline Ciprofloxacino & 9 & 64 & 5 & 42 & 1 & 25 & 1 & 20 & 2 & 100 \\
\hline Clorafenicol & NT & NT & 1 & 0 & NT & NT & NT & NT & NT & NT \\
\hline Colistina & 1 & 13 & 6 & 0 & NT & NT & 1 & 100 & 1 & 0 \\
\hline Clindamicina & NT & NT & NT & NT & NT & NT & NT & NT & NT & NT \\
\hline Daptomicina & NT & NT & NT & NT & 4 & 0 & NT & NT & NT & NT \\
\hline Eritromicina & NT & NT & NT & NT & NT & NT & NT & NT & NT & NT \\
\hline Ertapenem & 6 & 43 & 12 & 0 & NT & NT & 4 & 0 & NT & NT \\
\hline Fosfomicina & NT & NT & 6 & 0 & NT & NT & NT & NT & NT & NT \\
\hline Gentamicina & 9 & 64 & 3 & 25 & NT & NT & 1 & 20 & 4 & 100 \\
\hline Imipenem & 3 & 24 & 12 & 0 & NT & NT & 1 & 0 & 4 & 100 \\
\hline Linezolide & NT & NT & NT & NT & 3 & 0 & NT & NT & NT & NT \\
\hline Levofloxacino & 9 & 64 & 4 & 36 & 1 & 0 & 4 & 0 & 4 & 100 \\
\hline Meropenem & 5 & 39 & 12 & 0 & NT & NT & 4 & 0 & 4 & 100 \\
\hline Nitrofurantoina & 2 & 50 & 5 & 0 & 4 & 0 & 1 & 0 & NT & NT \\
\hline Penicilina & NT & NT & NT & NT & 4 & 0 & NT & NT & NT & NT \\
\hline Pipe+tazo & 8 & 57 & 12 & 0 & NT & NT & 4 & 0 & 4 & 100 \\
\hline Smt+tmp & 11 & 79 & 7 & 64 & NT & NT & 1 & 20 & 3 & 75 \\
\hline Tigeciclina & 10 & 0 & 6 & 0 & 4 & 0 & 3 & 100 & NT & NT \\
\hline Tetraciclina & NT & NT & 1 & 0 & NT & NT & NT & NT & 2 & 0 \\
\hline Vancomicina & NT & NT & NT & NT & 4 & 0 & NT & NT & NT & NT \\
\hline
\end{tabular}

NT: não testado; n: número de isolados bacterianos; \%: percentual de resistência; pipe+tazo: piperacilina + tazobactamsmt+tmp:sulfametoxazol + trimetoprima; amp+sub: ampicilina + sulbactam; amox+clav: amoxicilina + clavulanato

Os isolados de E. coli apresentaram os percentuais de resistência de $100 \%$ para cefazolina; $86 \%$ para ampicilina; $80 \%$ para cefuroxima; $71 \%$ para ampicilina +sulbactam; $64 \%$ para ceftriaxona e sulfametoxazol + trimetoprima; $60 \%$ para amoxilina + clavulanato; $50 \%$ para cefepime; $42 \%$ para ciprofloxacino; $36 \%$ para levofloxacino; $25 \%$ para gentamicina. Todos os isolados foram $100 \%$ sensíveis a amicacina, aztreonam, cefoxitina, clorafenicol, colistina, ertapenem, fosfomicina, imipenem, eropenem, nitrofurantoina, piperacilina + tazobactam, tigeciclina e tetraciclina (Tabela 3).

Os isolados de E. faecalis apresentaram os percentuais de resistência de $100 \%$ para ceftarolina e $25 \%$ para ciprofloxacino. A sensibilidade de 100\% foi observada para os seguintes antibióticos: ampicilina, daptomicina, linezolide, levofloxacino, tigeciclina e vancomicina (Tabela 3). Os isolados de $P$. mirabilis apresentaram os percentuais de resistência de $100 \%$ para tigeciclina e colistina; 
$20 \%$ para ampicilina, amicacina, ciprofloxacino, gentamicina e sulfametoxazol + trimetoprima. Todos os isolados foram $100 \%$ sensíveis a ampicilina + sulbactam, amoxilina + clavulanato, cefepime, cefoxitina, cefuroxima, ceftriaxona, cefotaxima, ertapenem, imipenem, levofloxacino, meropenem, nitrofurantoina e piperacilina + tazobactam (Tabela 3).

Para os isolados de A. baumannii foram observados percentuais de resistência de $100 \%$ para amicacina, cefepime, ceftazidina, ciprofloxacino, gentamicina, imipenem, levofloxacino, meropenem e piperacilina + tazobactam; $75 \%$ para sulfametoxazol + trimetoprima; $50 \%$ para: ampicilina+sulbactam. Os isolados foram $100 \%$ sensíveis somente a colistina e tetraciclina (Tabela 3).

\section{DISCUSSÃO}

Com o advento dos leitos reservados a cuidados prolongados na enfermaria da clínica médica, houve uma maior prevalência de pacientes advindos da UTI do hospital. O perfil de pacientes provenientes destes setores configura maiores chances de se encontrar pacientes que tenham sido submetidos à procedimentos invasivos, o que justifica o perfil de prevalência microbiana neste setor.

Durante o período do presente trabalho foi observado um total de 143 resultados positivos nas diferentes amostras analisadas, destes, os aspirados traqueais foram os que apresentaram maior positividade, enquanto as hemoculturas e as uroculturas apresentaram uma positividade semelhante, $15,4 \%$ e $16,1 \%$, respectivamente. Esses dados corroboram com os encontrados por Basso et $\mathrm{al}^{8}$, onde foi verificado, em UTIs de três hospitais da região de Porto Alegre (RS), que 46\% das bactérias isoladas foram provenientes de aspirados traqueais, $18 \%$ de hemoculturas e $18 \%$ de uroculturas. Em relação aos micro-organismos encontrados nos diferentes tipos de amostras, o presente trabalho corrobora com o estudo supracitado, onde foi observado maior ocorrência de $P$. aeruginosa em aspirados traqueais, $\mathrm{SCN}$ em hemoculturas e E. coli em uroculturas.

Em relação ao trato respiratório, no estudo realizado por Mota et $\mathrm{al}^{9}$, foi observado, em amostras de aspirados traqueais, as espécies de $A$. baumannii e $P$. aeruginosa como as mais ocorrentes, assim como no presente trabalho. Com relação ao perfil de resistência, os autores relataram um percentual de $82,8 \%$ a cefepime, ciprofloxacino e meropenem para A. baumannii. Essa elevada resistência corrobora com os achados do presente trabalho, onde foi observada uma resistência acima de $80 \%$ para estes 3 antibióticos. Em contrapartida, o perfil de sensibilidade dessa bactéria foi $100 \%$ somente para colistina, já no trabalho dos autores citados acima, o A. baumannii apresentou de 2,8\% resistência para esse antibiótico. No presente estudo foi observado um percentual de resistência de $100 \%$ para meropenem e imipinem, tanto para as espécies isoladas das amostras de secreções traqueais, como as de hemoculturas e uroculturas. Segundo Mendes et $\mathrm{al}^{10}$, alterações na permeabilidade da parede celular causadas pela perda de proteínas de porina ou redução da excreção das mesmas, comprometem a eficiência das cefalosporinas e aumentam o uso de carbapenêmicos nas infecções causadas pelas cepas de A. baumannii, que podem também ser agravados pela associação deste fator com a hiperexpressão de bombas de efluxo que expulsam o antibiótico da bactéria. Estes mecanismos em associação conferem aumento da resistência desta cepa aos betalactâmicos de espectro ampliado e carbapenêmicos.

A disseminação de espécies de $A$. baumanni multirresistentes coloca em risco a utilização da grande maioria dos antibióticos disponíveis na prática clínica, sendo então utilizado a ampicilina + sulbactam como uma opção terapêutica para o tratamento de cepas carbapenêmicos resistentes. ${ }^{11}$ No entanto, no presente estudo também foi identificada relevante resistência desta cepa a este antibiótico, nas uroculturas, $50 \%$ das cepas mostraram-se resistentes, nos aspirados traqueais $67 \%$ e nas hemoculturas $100 \%$. Segundo dados citados por Guimarães $^{12}$, as taxas resistência desta espécie são de $40 \%$ na Ásia, 51\% na Europa, 48\% na América Latina e $29 \%$ na América do Norte. Tais dados podem significar mais restrições no tratamento de infecções causadas por esta bactéria.

A. baumannii é frequentemente encontrado em pacientes hospitalizados, principalmente aqueles que estão criticamente doentes, com quebras de integridade da pele e com comprometimento das vias aéreas. ${ }^{13}$

Em relação a $P$. aeruginosa, o estudo realizado por Da Mota et $\mathrm{al}^{9}$, identificou um percentual de resistência de 33,33\% para imipinem e meropenem diferindo dos resultados do presente estudo, que foram 50 e $38 \%$ respectivamente. Os estudos diferiram também, na sensibilidadde dos isolados de $P$. aeruginosa, que no presente trabalho foram $100 \%$ sensíveis a piperacilina + tazobactam, porém no estudo de Da Mota et $\mathrm{al}^{9}$ foi de 7,4\%.

As infecções respiratórias por $P$. aeruginosa estão relacionadas com uma má função respiratória, baixa qualidade de vida e hospitalização frequente. Esta bactéria é altamente 


\section{Revista de Ensino, Ciência e Inovação em Saúde v.1, n. 1 (2020) 4-15}

versátil, capaz de tolerar condições de baixo oxigêniosendo capaz de sobreviver com baixos níveis de nutrientes e crescer em faixas de temperatura de 4 a $42{ }^{\circ} \mathrm{C}$,o quepermite que tenha a capacidade de se aderir, sobreviver em equipamentos médicos e outras superfícies hospitalares. ${ }^{14}$

Embora os carbapenêmicos sejam utilizados no tratamento de infecções pelas $P$. aeruginosa, o meropenem e o impenem, apresentaram resistência de $38 \%$ e $50 \%$ respectivamente no presente trabalho. A resistência específica aos carbapenêmicos pode ser atribuída à falta de permeabilidade porina (OprD), ao aumento da expressão de bombas de expulsão ativas (MexABOprD) e à produção de metaloenzimas. ${ }^{14}$

Em relação à sensibilidade a piperacilina + tazobactam, segundo Lodiseet al ${ }^{15}$ a infusão prolongada desse antibiótico tem sido eficaz no o tratamento de pacientes críticos infectados por $P$. aeruginosa, ratifica-se a afirmação destes autores com os dados do presente trabalho, onde foi observado uma sensibilidade de $77 \%$ para este antibiótico.

Além das cepas de A. baumannii e P.aeruginosa, também foi observada no presente estudo a relevante ocorrência da S. aureus (13\%), Melo et $a{ }^{16}$ também observaram a presença de $S$. aureus na cultura dos aspirados traqueais. Sabe-se que essa bactéria é encontrada na pele e nas fossas nasais de pessoas saudáveis, porém, é capaz de provocar doenças, que vão desde uma simples infecção (espinhas, furúnculos e celulites) até infecções graves como, pneumonia, meningite, endocardite, síndrome do choque tóxico, septicemia entre outras. ${ }^{17}$ Com relação ao perfil de resistência, também foi observado neste estudo que os isolados de S. aureus foram $100 \%$ resistentes à penicilina. Vale ressaltar, que também foi observada sensibilidade a 7 tipos de antibióticos testados, como, ciprofloxacino, doxiciclina, gentamicina, linezolide, minociclina, rifampicina, tigeciclina.

O aumento da resistência desta bactéria relaciona-se ao desenvolvimento de uma proteína ligadora de penicilina (PBP), que é uma proteína responsável pela síntese da parede celular. A PBP adicional desenvolvida (PBP2a) não possui afinidade aos betalactâmicos, assim, a codificação da PBP2a adicional não permite que estes antibióticos levem à lise bacteriana e aumenta a resistência à diversos betalactâmicos, inclusive oxacilina $^{18}$.

Segundo Speller et a ${ }^{19}$, cepas de $S$. aureus resistente à meticilina (MRSA) têm se mostrado resistentes à eritromicina, ciprofloxacina, gentamicina, clindamicina, trimetoprim, rifampicina, além dos beta-lactâmicos em geral, o que dificulta o tratamento e controle dessas infecções.

Nas hemoculturas analisadas, a espécie mais ocorrente foi a Staphylococcus coagulase negativa, foram encontrados $16(31 \%)$ isolados dessa bactéria. No estudo realizado por Dallacorte et $\mathrm{al}^{20}$, através da análise de laudos de 613 hemoculturas positivas em hospitais privados de Cascavel-PR, o SCN também apresentou alta relevância, sendo a segunda mais ocorrente no estudo (17\%). Com relação ao seu perfil de resistência observou-se $100 \%$ de resistência a ampicilina, eritromicina, levofloxacina, penicilina e piperacilina + tazobactam, além de valores acima de $80 \%$ de resistência a clindamicina e oxacilina. Todos os isolados de SCN foram $100 \%$ sensíveis a daptamicina, vancomicina e linezolida. Tais dados não corroboram com o estudo realizado por Dallacorte et $\mathrm{al}^{20}$, onde foi observado que a $S$. epidermidis, caracterizada por ser coagulase negativa, apresentou valores menores à $20 \%$ de resistência aos antibióticos eritromicina e oxacilina, enquanto no presente estudo observouse $100 \%$ e $88 \%$ de resistência, respectivamente, para esse grupo de bactérias. Já no estudo realizado por Alves et $\mathrm{al}^{21}$, o perfil de resistência observado corrobora com o presente estudo, S. epidermidis apresentou índices de $80 \%$ à oxacilina e $65 \%$ levofloxacina e também foi $100 \%$ sensível a linezolida.

Estes micro-organismos, gram positivos comumente encontrado na microbiota autoimune humana da pele e mucosas, com o passar dos anos foi acrescido com o gene $m e c A$, que codifica as proteínas ligadoras de penicilina (PBP) e favorece a síntese da parede celular bacteriana, assim, há a redução da afinidade aos beta-lactâmicos e a resistência tende a crescer cada vez mais. ${ }^{22}$

Nas hemoculturas também se destacam a elevada ocorrência das cepas de $S$. aureus e $K$. pneumoniae. As cepas de $S$. aureus no presente estudo apresentaram $100 \%$ de resistência aos antibióticos do grupo das penicilinas. Do mesmo modo, aproximando-se do resultado obtido neste trabalho, o estudo realizado por Leão et $\mathrm{al}^{23}$ esta bactéria apresentou em seu perfil de $100 \%$ de resistência a ampicilina, e $100 \%$ de sensibilidade a linezolida e vancomicina.

Quanto a $K$. pneumoniae isoladas de hemoculturas, dados obtidos por Leão et $\mathrm{al}^{23}$, demostraram índices de resistência de $70 \%$ para sulfametoxazol + trimetropima, que no presente estudo apresentou índice de resistência de $60 \%$ e de $100 \%$ de sensibilidade para os carbapenêmicos, assim como no presente estudo. 
O aumento da resistência da $K$. pneumoniae a antimicrobianos tem se tornado um grande problema de saúde pública. Seu mecanismo de resistência é estimulado pelo uso inadequado de antimicrobianos, que induz a hiperprodução de beta-lactamases como AmpC, carbapenemases do tipo serina (KPC) e metalo-beta-lactamases (MBL). Estas enzimas hidrolisam os anéis betalactâmicos e podem ocasionar a resistência a betalactâmicos de importância clínica, como penicilinas, cefalosporinas e carbapenens. Em nosso estudo foi observado que essa espécie estava presente nos aspirados traqueais, hemoculturas e uroculturas, corroborando com os encontrados por Reis et $\mathrm{al}^{24}$, que ao comparar dados da UTI e enfermaria observaram que a $K$. pneumoniae, foi a mais comumente encontrada, do mesmo modo que no estudo realizado por Mota et $\mathrm{al}^{9}$, onde foi observado a prevalência de $35,5 \%$ destas bactérias nas amostras analisadas da UTI.

Nas uroculturas, a K. pneumoniae também mostrou relevante ocorrência. No estudo realizado por Pires et $\mathrm{al}^{25}$, entre os bacilos gram-negativos, $K$. pneumoniae foi a segunda espécie mais ocorrente $(6,8 \%)$ e apresentou perfil de sensibilidade de $90 \%$ para amicacina e $86 \%$ para gentamicina. No presente estudo, esta bactéria destacou-se como a mais encontrada e apresentou índices de sensibilidade de 100\% para os mesmos antibióticos citados.

A incidência da $E$. coli nas uroculturas também se mostrou relevante, representando $25 \%$ das uroculturas positivas. Em um estudo realizado por Narciso et $\mathrm{al}^{26}$, foi observado a ocorrência de $76 \%$ de E. coli em um total de 577 amostras coletadas. Do mesmo modo, no estudo realizado por Pires et $\mathrm{al}^{25}$, a $E$. coli foi a bactéria mais isolada, representando $63 \%$ das uroculturas positivas no serviço ambulatorial.

Quanto ao perfil de resistência, foi observado que a E. coli no presente estudo apresentou $100 \%$ de resistência somente para o antibiótico cefazolina e índices acima de $80 \%$ para ampicilina e cefuroxina. A sensibilidade de $100 \%$ dos isolados foi observada para amicacina, aztreonam, cefoxitina, cloranfenicol, colistina, fosfomicina, ertapenem, imipenem, meropenem, nitrofurantoina, piperaciclina + tazobactam tigeciclina e tetraciclina. Os valores observados por Narciso et $\mathrm{al}^{26}$, foram semelhantes mostrando um índice de sensibilidade à fosfomicina de $99 \%$, no entanto, os resultados divergiram na sensibilidade para cefuroxima que foi de $97 \%$. Já no estudo realizado por Pires et $\mathrm{al}^{25}$ os valores de sensibilidade aproximam-se dos valores observados no presente estudo, a E. coli demonstrou $99 \%$ de sensibilidade a amicacina e
$97 \%$ a nitrofurantoína, bem como, apresentou $80 \%$ de resistência a ampicilina.

As cepas de E. coli se adaptam rapidamente às mudanças do microambiente onde estão inseridas, logo, alguns mecanismos de resistência se desencadeiam e aumentam a resistência dessa bactéria. Segundo Baptista ${ }^{22}$, a bomba de efluxo é a principal responsável pela expulsão dos antibióticos do meio intracelular para o meio extracelular, porém, ocorre comumente a mutação do gene acrR e a atividade desta bomba de efluxo é aumentada causando maior resistência dessa bactéria. Do mesmo modo, essas bactérias podem ser estimuladas à maior produção de enzimas betalactamases de espectro estendido (ESBL) ou sofrer mutações genéticas que agem na enzima DNA girase e conferem maior resistência aos fármacos.

Logo, a partir deste conhecimento é possível identificar as espécies mais ocorrentes nas diferentes amostras analisadas e o alto perfil de resistência das mesmas. Essa elevada resistência observada é capaz de agravar as complicações clínicas e ocasionar longos períodos de internamento, maiores custos hospitalares e altos índices de mortalidade. Embora nem todos os casos de IRAS sejam evitáveis, conhecer o perfil destas infecções permite o estabelecimento de protocolos preventivos e tratamentos efetivos. Portanto, o presente trabalho contribui para vigilância e controle das IRAS, bem como, para redução das consequências destas infecções.

\section{REFERÊNCIAS}

1Padoveze MC, Fortaleza CMCB. Infecções relacionadas à assistência à saúde: desafios para a saúde pública no Brasil. Rev. Saúde Públ 2014; 48(6):995-1001. https://doi.org/10.1590/s0034$\underline{8910.2014048004825}$

${ }^{2}$ Miller AC, Polgreen LA, Polgreen PM. Optimal Screening Strategies for Healthcare Associated Infections in a Multi-Institutional Setting. PLoS computational biology 2014; 10:e1003407. https://doi.org/10.1371/journal.pcbi.1003407

${ }^{3}$ WHO Guidelines on Hand Hygiene in Health Care. First Global Patient Safety Challenge Clean Care is Safer Care. World Health Organizations; 2009. Disponível em: < https://www.who.int/patientsafety/events/05/GPS C Launch ENGLISH FINAL.pdf $>$

${ }^{4}$ Giunta APN, Lacerda RA. Inspeção dos Programas de Controle de Infecção Hospitalar dos 


\section{Revista de Ensino, Ciência e Inovação em Saúde v.1, n. 1 (2020) 4-15}

serviços de saúde pela Vigilância Sanitária: diagnostico de situação. Revista da Escola de Enfermagem da USP 2006;40(1):6470. https://doi.org/10.1590/S00806234200600010 $\underline{0009}$

${ }^{5}$ Agência Nacional de Vigilância Sanitária (ANVISA). Critérios Diagnósticos de Infecções Relacionadas à Assistência à Saúde. Brasília: ANVISA, 2017. Disponível em: < https://www.gov.br/anvisa/pt-br >

${ }^{6}$ Sasaki VDM, Romanzini AE, Jesus APM, et al. Vigilância de Infecção de sítio cirúrgico no pósalta hospitalar de cirurgia cardíaca reconstrutora. Texto \& contexto enfermagem 2011;20(2):32832. https://doi.org/10.1590/S0104$\underline{07072011000200015}$

${ }^{7}$ Hidalgo G, Ponton A, Fatisson J, et al. Induction of a state of iron limitation in uropathogenic Escherichia coli CFT073 by cranberry-derived proanthocyanidins as revealed by microarray analysis. Appliedand Environmental Microbiology 2011; 77(4):1532-1535. https://doi.org/10.1128/AEM.02201-10

${ }^{8}$ Basso ME, Pulcinelli RSM, Aquino ARC, et al. Prevalência de infecções bacterianas em pacientes internados em uma unidade de terapia intensiva (UTI). Revista Brasileira de Análises Clínicas 2016; 48(4):383-8. https://doi.org/10.21877/24483877.201600307

${ }^{9}$ Mota FS, Oliveira HA, Souto RCF. Perfil e prevalência de resistência aos antimicrobianos de bactérias Gram-negativas isoladas de pacientes de uma unidade de terapia intensiva. Revista Brasileira de Análises Clínicas 2018; 50 (3):270-277.

https://doi.org/10.21877/24483877.201800740

${ }^{10}$ Mendes RE, Castanheira M, Pignatari AC, et al. Metalo-beta-lactamases. Jornal brasileiro de patologia e medicina laboratorial 2006; 42(2):10313.

https://doi.org/10.1590/S16762444200600020000 $\underline{7}$

${ }^{11}$ Viana GF, Saalfed SM, Moreira RR, et al. Can ampicillin/sulbactam resistance in Acinetobacter baumannii be predicted accurately by disk diffusion? Journal of global antimicrobial resistance 2013; 1(4):22122. https://doi.org/10.1016/j.jgar.2013.07. $\underline{001}$

${ }^{12}$ Guimarães MP. Ocorrência de Acinetobacter baumannii Resistente aos Carbapenêmicos em
Pneumonias Associadas a Ventilação Mecânica em uma Unidade de Terapia Intensiva de Adultos Mista de um Hospital Universitário Brasileiro: fatores de risco e prognóstico [manuscrito]. Uberlândia (MG): Universidade Federal de Uberlândia, 2011. Disponível em < https://repositorio.ufu.br/bitstream/123456789/16 670/1/Diss\%20Munick.pdf >

${ }^{13}$ Scarcella ACA, Scarcella ASA, Beretta ALRZ. Infecção relacionada à assistência à saúde associada a Acinetobacter baumannii: revisão de literatura. Revista Brasileira de Análises Clínicas 2015;49(1):18-21. https://doi.org/10.21877/24483877.201600361

${ }^{14}$ Ochoa SA, López-Montiel F, Escalona G, et al. Pathogenic characteristics of Pseudomonas aeruginosa strains resistant to carbapenems associated with bio film formation. Boletin Medico del Hospital Infantil de Mexico 2013; 70(2), 138-150. Disponível em < https://www.medigraphic.com/pdfs/bmhim/hi2013/hii132j.pdf >

${ }^{15}$ Lodise-Jr TP, Lomaestro B, Drusano GL. Piperacillin-tazobactam for Pseudomonas aeruginosa a infection: clinical implications of anextended-infusion dosing strategy. Clinical Infectious Diseases 2007; 44(3), 357363. https://doi.org/10.1086/510590

16 Melo EM, Silva TJG, Silva JLA, et al. Major bacteria in urine cultures and tracheal aspirate from patients with infectious diseases. Revista de Enfermagem da UFPI 2016;4(3), 305. https://doi.org/10.26694/reufpi.v4i3.4409

${ }^{17}$ Santos ALD, Santos DO, Freitas CCD, et al. Staphylococcus aureus: visitando uma cepa de importância hospitalar. Jornal Brasileiro de Patologia e Medicina Laboratorial 2007;43(6), 413-

423. https://doi.org/10.1590/S1676244420070006 $\underline{00005}$

${ }^{18}$ Gelatti LC, Bonamigo RR, Becker AP, et al. Staphylococcus aureus resistentes à meticilina: disseminação emergente na comunidade. Anais brasileiros de dermatologia 2009;84(5):501-6. http://dx.doi.org/10.1590/S036505962009000500 $\underline{009}$

${ }^{19}$ Speller DCE, Johnson AP, James D. Resistance to methicillin and other antibiotics in isolates of Staphylococcus aureus from blood and cerebrospinal fluid, England and Wales, 1989-95. 
Revista de Ensino, Ciência e Inovação em Saúde v.1, n. 1 (2020) 4-15

Lancet 1997; 350(9074):323-5. https://doi.org/10.1016/s01406736(97)12148-1

${ }^{20}$ Dallacorte TS, Indras DM, Teixeira JJV, et al. Prevalência e perfil de sensibilidade antimicrobiana de bactérias isoladas de hemoculturas realizadas em hospitais particulares. Revista do Instituto Adolfo Lutz 2016; 75:1702. Disponível em

http://www.ial.sp.gov.br/resources/insitutoadolfolutz/publicacoes/rial/10/rial75_completa/art igos-separados/1702.pdf >

21 Alves LNS, Oliveira CR, Silva LAP, et al. Hemoculturas: estudo da prevalência dos microrganismos e o perfil de sensibilidade dos antibióticos utilizados em unidade de terapia intensiva. Journal of the Health Sciences Institute 2012;30(1):44-7. Disponível em < https://pesquisa.bvsalud.org/portal/resource/pt/lil644794 >

22 Baptista MGFM. Mecanismos de Resistência aos Antibióticos [tese]. Lisboa (PT): Universidade Lusófona de Humanidades e Tecnologias; 2013. Disponível em https://recil.grupolusofona.pt/handle/10437/3264 $>$

${ }^{23}$ Leão LSNO, Passos XS, Reis $\mathrm{C}$, et al. Fenotipagem de bactérias isoladas em hemoculturas de pacientes críticos. Revista da
Sociedade Brasileira de Medicina Tropical 2007;40(5):537-540.

http://dx.doi.org/10.1590/S003786822007000500 $\underline{009}$

${ }^{24}$ Reis HPLC, Vieria JB, Magalhães DP, et al. Avaliação da resistência microbiana em hospitais privados de Fortaleza - Ceará. Revista brasileira de farmácia 2013; 94 (1): 83-87. Disponível em < http://www.repositorio.ufc.br/handle/riufc/6941 >

${ }^{25}$ Pires MCS, Frota KS, Junior POM, et al. Prevalência e suscetibilidades bacterianas das infecções comunitárias do trato urinário, em Hospital Universitário de Brasília, no período de 2001 a 2005. Revista da Sociedade Brasileira de Medicina Tropical 2007; 40(6): 643-647. http://dx.doi.org/10.1590/S003786822007000600 $\underline{009}$

${ }^{26}$ Narciso A, Fonseca F, Cerqueira SA, et al. Susceptibilidade aos antibióticos de bactérias responsáveis por cistites não complicadas: estudo comparativo dos isolados de 2008 e 2010. Acta Urológica 2011;1: 16-21. Disponível em < https://www.apurologia.pt/acta/1-2011/susc-antbact-cist.pdf $>$ 